This is a postprint version of the following published document:

A. Tapetado, C. Vázquez, X. Soldani, H. Miguélez, D. S. Montero. Temperature sensor based on fiber optic pyrometer in material removal processes. OFS-22, 22 nd International Conference on Optical Fibre Sensors. Proc. of SPIE Vol. 8421 (2012) 84212V, pp. 1-4. Available in http://www.dx.doi.org/10.1117/12.970276 .

(C) 2015 Society of Photo Optical Instrumentation Engineers. One print or electronic copy may be made for personal use only. Systematic electronic or print reproduction and distribution, duplication of any material in this paper for a fee or for commercial purposes, or modification of the content of the paper are prohibited. 


\title{
Temperature sensor based on fiber optic pyrometer in material removal processes
}

\author{
A. Tapetado ${ }^{* a}$, C. Vázquez ${ }^{\mathrm{a}}$, X. Soldani ${ }^{\mathrm{b}}, \mathrm{H}_{\text {. Miguélez }}^{\mathrm{b}}$, D. S. Montero ${ }^{\mathrm{a}}$ \\ ${ }^{a}$ Electronics Technology Dpt., ${ }^{\mathrm{b}}$ Mechanical Engineering Dpt., Carlos III University of Madrid \\ Avda. de la Universidad, 30, Leganés (Madrid), Spain
}

\begin{abstract}
In this work, different non-contact fiber-optic pyrometers have been developed for measuring localized temperatures on material removal area during mechanizing processes. Designs are developed for adaptation to the harsh measuring conditions on specific cutting tool machinery and using commercial optoelectronics and fiber-optic components for resolution enhancement. A $0.1 \mathrm{~dB} /{ }^{\circ} \mathrm{C}$ sensitivity at $300{ }^{\circ} \mathrm{C}$ is obtained, and calibration curves at $1100 \mathrm{~nm}, 1300 \mathrm{~nm}, 1550$ $\mathrm{nm}$ and $1610 \mathrm{~nm}$ are reported. Different reception circuits are used for testing resolution limits, higher bandwidths imply greater noise and worst results as expected.
\end{abstract}

Keywords: fiber-optic sensors, non-contact temperature sensor, metal cutting process, one-color pyrometer, two-color pyrometer.

\section{INTRODUCTION}

Temperature measurement is one of the most complex subjects in metal cutting operations due to the difficulty in making those measurements very close to the cutting edge. Temperature affects both the tool and the workpiece, being the heat generated in the cutting process the main cause of surface degradations, wear and thermo-mechanical failure, in particular, cracking. The primary effect of temperature is on tool wear. Although there are different tool wear mechanisms, it is well known that the progressive tool wear is mainly produced by temperature dependent mechanisms [1]. Both the maximum temperature and the temperature gradient also influence subsurface deformation, metallurgical structural alterations in the machined surface, and residual stresses in the finished component.

In order to predict the consequences of thermal damage, several techniques have been developed to measure the temperature in material removal process such as resistance methods and thermocouples [2]. Even though thermocouples are inexpensive and easy to use transducers, they have several disadvantages; they can interfere with the flow of heat, they have limited transient response, it is difficult to estimate the gradient of temperature with this technique, and they are contact sensors which cannot be easily located on limited spaces such as an edge of the cutting tool in material removal operations. In addition to thermocouples, infrared (IR) radiation technique is the second most used method for temperature measurement in machining. It performs a non-intrusive technique, so the IR radiation technique does not interfere with the flow of heat as thermocouples do. It also provides a very fast response, which is a mandatory requirement in high speed machining temperature measurements. However, the need to know the exact surface emissivity, the chip obstruction, and the low signal levels are the main disadvantages of this technique [3]. Recently it has been used a two-color fiber optic pyrometer for measuring the cutting tools edge temperature in finish hard turning [4] but for temperatures greater than $800^{\circ} \mathrm{C}$. These two-color fiber-optic pyrometers are developed for reducing the uncertainty associated with emissivity, but at the expense of reducing its sensitivity and temperature range [4-6].

In this work, different fiber-optic pyrometers have been developed for localized temperature measurements on cutting tools during mechanizing processes. The novelty of the designs is based on assuring adaptation to the harsh measuring conditions. In addition to, these solutions take advantage of commercial optoelectronics and fiber-optic components well established on Wavelength Division Multiplexing optical communications networks for improving resolution, and consequently the availability to measure at lower temperatures.

*atapetad@ing.uc3m.es; phone+3491624 9164; fax +34916249430 

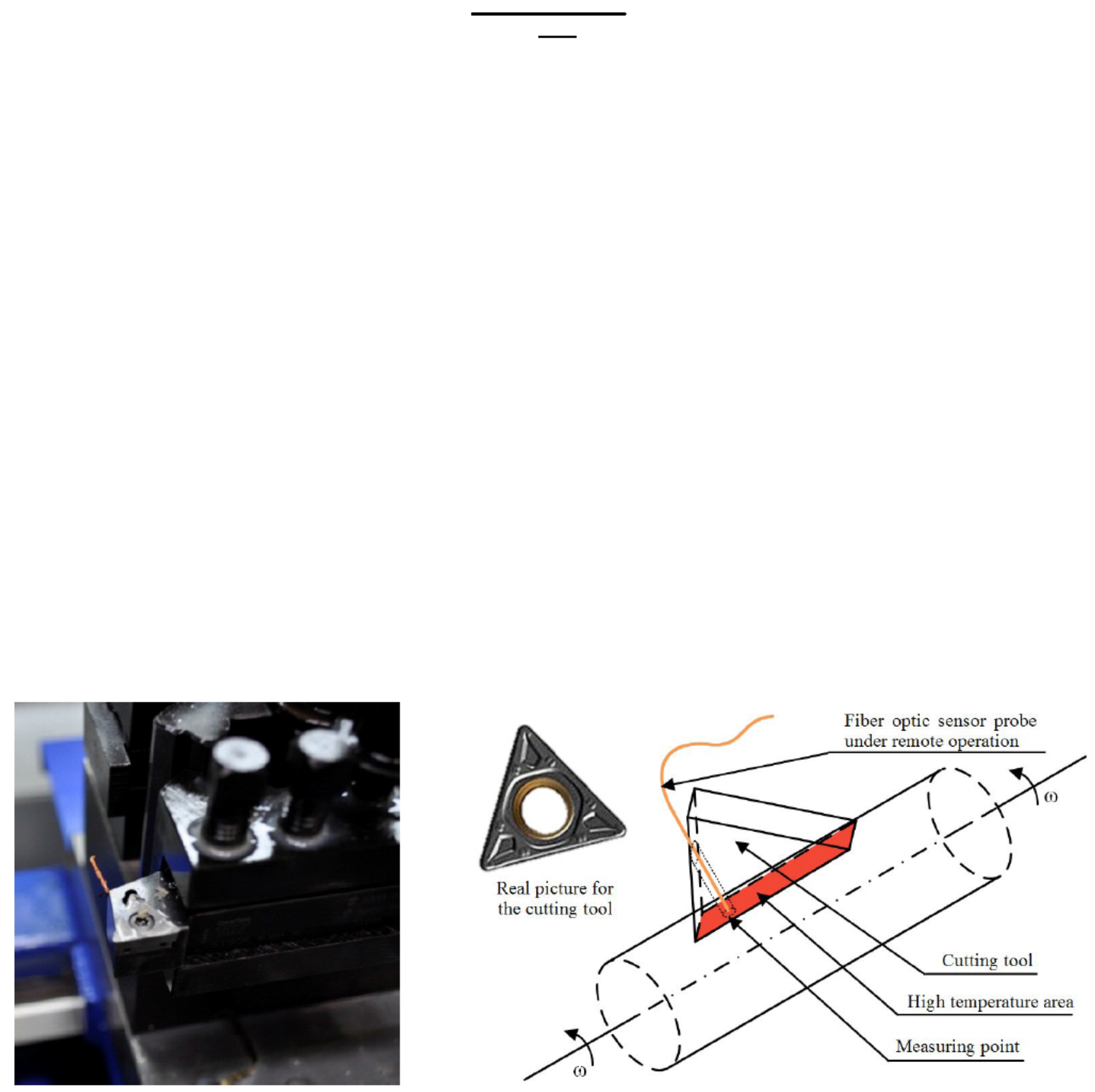

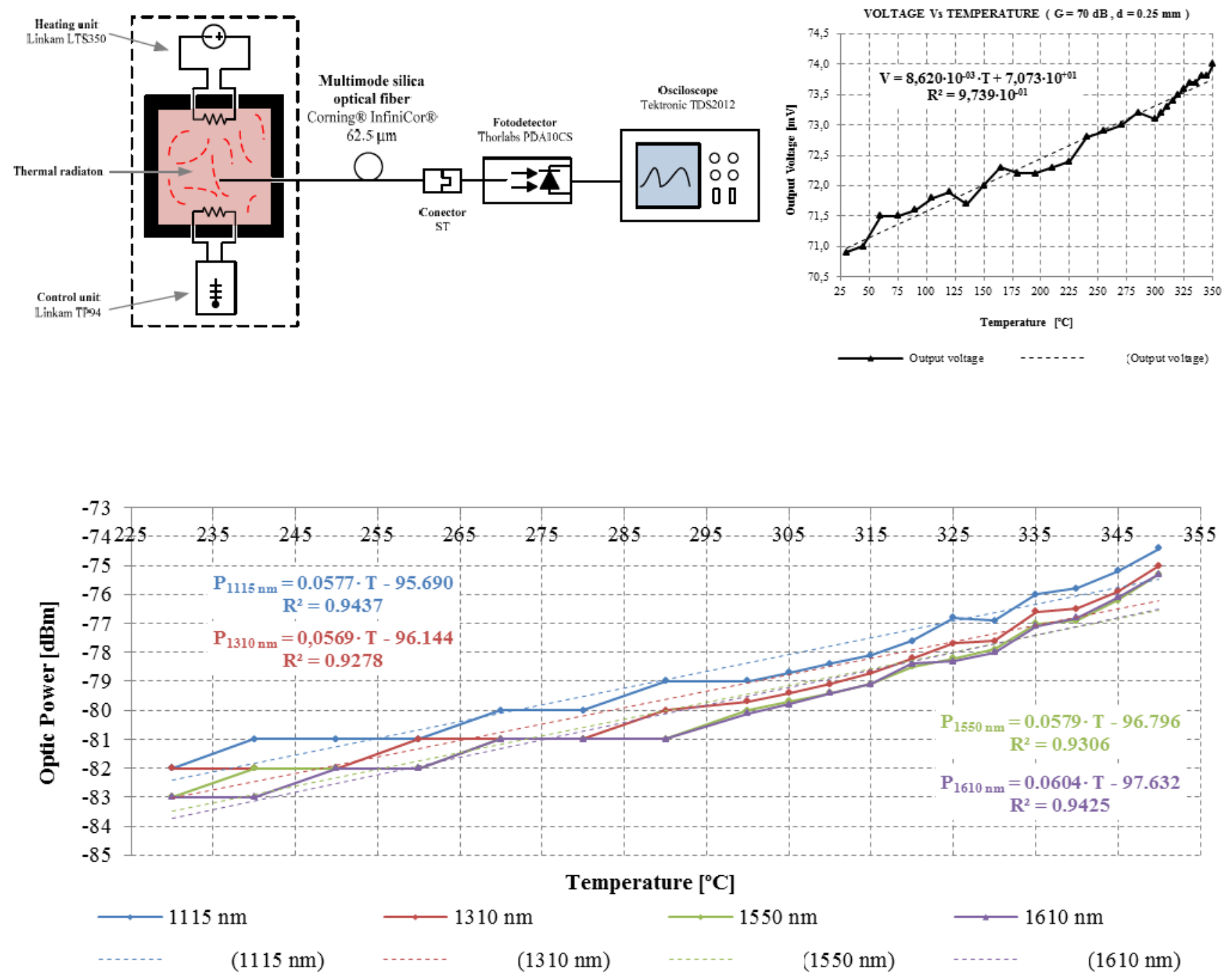
The sensor calibration curve for the one-color pyrometer was measured using the set-up shown in Fig. 2(a). The fiber sensor was fixed at a distance of $0.25 \mathrm{~cm}$ from rectangular highly conductive metal base plate. The temperature of the latter was controlled using a heating source (Linkam ${ }^{\circledR}$ LTS350) and a controller unit (Linkam ${ }^{\circledR}$ TP94). The controller and heating units give a temperature range from $+30{ }^{\circ} \mathrm{C}$ to $+350{ }^{\circ} \mathrm{C}$. Using the accurate temperature monitor of the controller unit, the voltage from radiance intensity was measured using a photodetector (Thorlabs ${ }^{\circ}$ PDA10CS) and an oscilloscope (Tektronic $\otimes$ TDS2012). $15{ }^{\circ} \mathrm{C}$ intervals for a temperature range from $+30^{\circ} \mathrm{C}$ to $+300{ }^{\circ} \mathrm{C}$ and $5{ }^{\circ} \mathrm{C}$ intervals for a temperature range from $+300{ }^{\circ} \mathrm{C}$ to $+350^{\circ} \mathrm{C}$ were tested. Experimental calibration curves are shown in Fig. 2(b). It should be noted that there is too much noise for temperatures below $250^{\circ} \mathrm{C}$.

On the other hand, the sensor calibration curve for the two-color pyrometer was measured using the same set-up shown in Fig. 2(a), but the Optical-to-Electrical (O/E) converter and the oscilloscope is replaced by an optical power meter $($ EXFO® PF-1100).

Intensity radiance at each discrete wavelength was measured at $15{ }^{\circ} \mathrm{C}$ intervals for a temperature range from $+230{ }^{\circ} \mathrm{C}$ to $+300{ }^{\circ} \mathrm{C}$, and $5{ }^{\circ} \mathrm{C}$ intervals for a temperature range from $+300^{\circ} \mathrm{C}$ to $+350{ }^{\circ} \mathrm{C}$. The minimum and maximum range was limited by the optical power meter resolution $(-85 \mathrm{dBm})$. Results are shown in Fig. 3, including a linear approximation for each calibration curve. From $+300{ }^{\circ} \mathrm{C}$ to $+350{ }^{\circ} \mathrm{C}$, a sensitivity of $0.1 \mathrm{~dB} /{ }^{\circ} \mathrm{C}$ at $1300 \mathrm{~nm}$ is obtained.

\section{CONCLUSIONS}

In this work, two fiber-optic sensors based on thermal radiation have been designed to measured temperature in material removal processes. The main advantages of these sensors are the ability to realize non-contact temperature measurements, avoiding interference with heat flow, the capability to measure temperatures rapidly, the small size of the sensing head and the low cost. From the experimental results, it can be seen that the best option for measuring temperature in material removal processes, using mature optical communications devices, is a two-color pyrometer because emissivity dependence is overcome and wavelength division multiplexing devices are prepared for working with narrow bandwidths. Using off-the-shelf equipment designed for detection of very low signal levels, sensitivities of $0.1 \mathrm{~dB} /{ }^{\circ} \mathrm{C}$ at $1300 \mathrm{~nm}$ are obtained without special collimating optics, unable to be easily placed in this measuring framework.

\section{ACKNOWLEDGEMENTS}

This work has been sponsored by the Spanish Ministry of Science and Innovation within project TEC2009-14718-C0303 and by FACTOTEM-II-C: S2009/ESP-1781 of Comunidad Autónoma de Madrid.

\section{REFERENCES}

[1] Wanigarathne, P. C., Kardekar, A. D., Dillon, O. W., Poulachon, G. and Jawahir, I. S., "Progressive tool-wear in machining with coated grooved tools and its correlation with cutting temperature", Wear, vol. 259, 1215-1224 (2005).

[2] Kennedy, F., Frusescu, D. and Li, J., "Thin film thermocouple arrays for sliding surface temperature measurement", Wear, vol. 207, 46-57 (1997).

[3] Dinc, C., Lazoglu, I. and Serpenguzel, A., "Analysis of thermal fields in orthogonal machining with infrared imaging", Journal of Materials Processing Technology, vol. 198, 147-154 (2008).

[4] Tanaka, R., et al., "Cutting Tool Edge Temperature in Finish Hard Turning of Case Hardened Steel", Key Engineering Materials, vols.407-408, 538-541 (2009).

[5] Muller, B. and Renz, U., "Development of a fast fiber-optic two-color pyrometer for the temperature measurement of surfaces with varying emissivities," Review of Sci. Instruments, vol. 72, pp. 3366-3374 (2001).

[6] Thevenet, J., Siroux, M. and Desmet, B., "Measurements of brake disc surface temperature and emissivity by twocolor pyrometry," Applied Thermal Engineering, vol. 30, pp. 753-759 (2010).

[7] Hernandez, D., Olalde, G., Beck, A. and Milcent, E., "Bicolor pyroreflectometer using an optical fiber probe", Review of Sci. Instruments, vol. 66, pp. 5548-5551 (1995).

[8] Mason, R. A., "Optical fibre radiation pyrometer", US Patent, US4799787 (1989). 